\title{
The unexpected twist in the plot: incarcerated diaphragmatic hernia complicating colonoscopy
}

A 76-year-old woman was referred for surveillance colonoscopy. She had a history of a large sliding hiatal hernia, confirmed by both chest radiography and upper endoscopy. She had no history of trauma and 6 years ago she underwent a full colonoscopy and polypectomy uneventfully. The colonoscope was advanced $50 \mathrm{~cm}$ to the splenic flexure, at which point a very tight angle could not be passed and the lumen was obscured. After a few unsuccessful attempts to advance were made, the scope was withdrawn and the examination was terminated. In the recovery room, the patient complained of worsening abdominal pain and vomiting. She was transferred to the emergency room for further evaluation. Abdominal radiography showed a largebowel loop in the left hemithorax with a distended right colon ( $\bullet$ Fig. 1 ). Abdominal computed tomography (CT) revealed that the whole stomach, part of the duodenum, and a large segment of transverse colon were all in the chest ( Fig. 2). The proximal transverse colon, ascending colon, and cecum were severely dilated. An urgent explorative laparotomy revealed an incarcerated loop of transverse colon, which has herniated through the diaphragm. An ileostomy and right extended hemicolectomy was carried out. In the past, a few case reports have described strangulation of intestinal contents during colonoscopy as a result of the exacerbation of transdiaphragmatic hernias [1$4]$, but there have been no previous reports of deterioration and incarceration of a preexisting large sliding hiatal hernia during colonoscopy. Although a past history of a large sliding hiatal hernia was known in our patient, no special precautions were executed. Air insufflation in combination with increased abdominal pressure may protrude abdominal contents through a weakened diaphragm. Trapping of the endoscope and extreme angulation causes the lumen to seem ob- scured. In light of the present case, endoscopists should be aware of this phenomenon.

Endoscopy_UCTN_Code_CPL_1AJ_2AH

Competing interests: None

\section{B. Koslowsky, T. Adar, M. Mahamid, B. Melamud, E. Goldin, L. Ozick}

Digestive Disease Institute, Shaare Zedek Medical Center, Jerusalem, Israel

\section{References}

1 Sodhi SS, Zech LAJr, Batura Vet al. Diaphragmatic hernia with strangulated loop of bowel presenting after colonoscopy: case report. Int Arch Med 2009; 2: 38

2 Baumann UA, Mettler M. Diagnosis and hazards of unexpected diaphragmatic hernias during colonoscopy: report of two cases. Endoscopy 1999; 31: 274-276

3 Dobres C, Fan J, Schattner $M$ et al. Transdiaphragmatic hernia and hypoxemia during colonoscopy. Anesthesiology 2004; 101: 811

4 Chae HS, Kim SS, Han SW et al. Herniation of the large bowel through a posttraumatic diaphragmatic defect during colonoscopy: report of a case. Dis Colon Rectum 2002; 45: $1261-1262$

\section{Bibliography}

DOI http://dx.doi.org/

10.1055/s-0032-1326118

Endoscopy 2013; 45: E11

(c) Georg Thieme Verlag KG

Stuttgart · New York

ISSN 0013-726X

\section{Corresponding author}

\section{B. Koslowsky}

Digestive Diseases Institute

Shaare Zedek Medical Center

Affiliated with the Hebrew University, РОВ 3235

12 Bayit Street

Jerusalem

Israel 91031

Fax: +972-2-6666050

binyaminkos@szmc.org.il

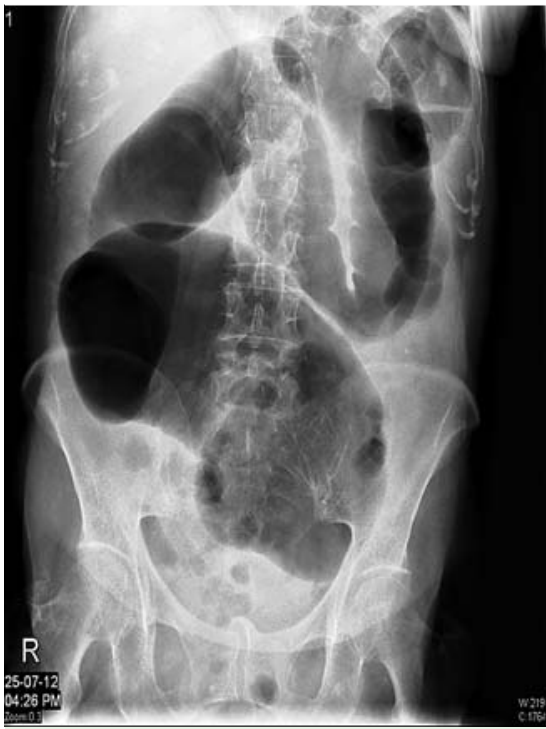

Fig. 1 Plain abdominal radiograph performed shortly after colonoscopy in a 76-year-old woman with a history of a large sliding hiatal hernia. Dilated cecum and proximal colon are seen.

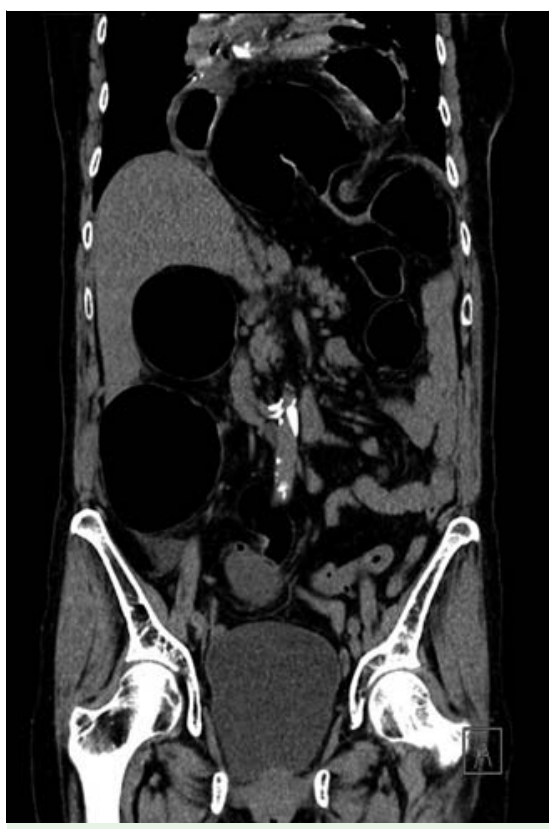

Fig. 2 Coronal abdominal computed tomography (CT) shows long loop of transverse colon, stomach, and part of duodenum in the chest. A very large hiatal hernia can be seen. 